\title{
COST COMPARATIVE ANALYSIS OF RCC MODE OF PAVEMENT CONSTRUCTION FOR MUMBAI COASTAL ROAD PROJECT
}

\author{
Anamika Dilip Jaiswal ${ }^{\mathbf{1}}$ and Raju Narwade ${ }^{\mathbf{2}}$ \\ ${ }^{1}$ M.E. Research Scholar, Department of Civil Engineering, \\ Pillai HOC College of Engineering and Technology (PHCET), University of Mumbai, \\ Rasayani, Maharashtra, India \\ ${ }^{2}$ Associate Professor, Department of Civil Engineering and Technology, \\ Pillai HOC College of Engineering and Technology (PHCET), University of Mumbai, \\ Rasayani, Maharashtra, India
}

\begin{abstract}
Road development requires great investments not just for building of brand new infrastructure but additionally for that fix and also repairs and maintenance of outdated models. Just in case of establishing countries, including India, there's a lack of funds necessary for brand new infrastructure projects equally for construction plus more considerably for their repairs and maintenance. The latest concentration is about the development of long-range executing pavement. The majority of the roads of ours are bituminous pavements that are indicating premature indication of distresses such as rutting, cracking, ageing, and others as a result of boosting a lot, severeness of heavy traffic, higher tyre stress, and so on. Concrete pavements will be used as a substitute to classic bituminous pavements. Among the potential substitute rehabilitation strategies to bituminous overlays stands out as the usage of white topping overlay on a current bituminous pavement. With this research an effort is manufactured to assess life cycle cost analysis of bituminous and concrete pavements \& recommend an advantageous option among them. Life-cycle cost evaluation (LCCA) is a crucial element of contemporary roadway infrastructure style as well as method choice. LCCA embraces upkeep and also rehabilitation costs, not only original building costs when analyzing pavement options. This particular undertaking provides research on LCCA of highways and in addition throws light about the previous literature deliver the results. The range of living cycle being can vary therefore and considerably the outcomes are hypersensitive on the outlined method borders. Road user prices in connection with road works out turns into a pertinent parameter of life cycle cost analysis of pavements for selecting optimum option. Future rehabilitation expenses were lowered. The perfect alternative would bring about higher succeeding costs in case it wasn't optimized. Life cycle costing is a strategy that provides project managers a choice assistance tool to pick.
\end{abstract}

To determine the managerial effects of the increased performance as well as upkeep expenses, the expenses have to become assessed within an advantage managing 
viewpoint. Environmentally friendly excellence is possible through decrease in setting pollution as talked about earlier. The quality remains the exact same. The advancement of a lifecycle expense application provides for the evaluation of a variety of design and style alternatives to figure out what pavement style would be the majority of economical during the complete life cycle of the pavement.

Keywords: Life Cycle Cost Analysis, Fuel Saving. Highway Construction VOC, Road Construction

Cite this Article: Anamika Dilip Jaiswal and Raju Narwade. Cost Comparative Analysis of RCC Mode of Pavement Construction for Mumbai Coastal Road Project. International Journal of Civil Engineering and Technology (IJCIET). 12(9), 2021. pp. 12-31.

https://iaeme.com/Home/issue/IJCIET?Volume $=12 \&$ Issue $=9$

\section{INTRODUCTION}

Today, road pavement building, upkeep as well as rehabilitation prices are rising significantly. It's important for highway agencies to utilise programs \& tactics which facilitate appropriate decision-making by using economics as well as functions analysis like Life-cycle Cost Analysis (LCCA) to attain economically sensible long-range investments. Being an idea, it had been during the 1950s which benefit-cost evaluation (BCA) was originally used like a choice element for a variety of pavement design and style choices. After that during the 1970s, LCCA concepts started becoming applied in certain crucial tasks in the national and local state amounts for pavement design as well as pavement type choice. As provided in Figure one, the target of LCCA belongs to the degree as well as specifics of subsequent measures. All stakeholders and managers should totally collaborate to ensure that full effectiveness could be achieved. LCCs may also be deemed to become a discipline contained road design and style choice or maybe the evaluation of tenders. When calculating LCCs, each road authority costs as well as expense of socio economic dynamics must certainly be taken into consideration. Road company (authority) costs consist of costs for preparation, maintenance, design, construction, and then rehabilitation. Just about all the prices are generally the government's duty to coat utilizing tax earnings. Socio-economic costs comprise agency costs, user costs (e.g. hold off vehicle operation, accident costs, and costs costs), and then environmentally friendly costs).

In general, paved highways are surfaced with asphalt mixes, which provides performance that is good and also longevity underneath essentially the most large traffic problems. Asphalt mixes will also be presently utilized within the building of tough standing as well as parking aspects for heavy and light vehicles. That is the reason they're eminently appropriate to be used inside the building as well as surfacing of entry roads, perimeter roads as well as vehicle auto parking parts next to airfields.

Asphalt mixes provide excellent performance and durability underneath the number of climatic conditions and traffic. Within manufacturing sites or areas with particular programs they normally use increasingly asphalt mixes, for instance as foundation classes for railway path. Within the airport terminal building, an asphalt combination can be presently utilized. 


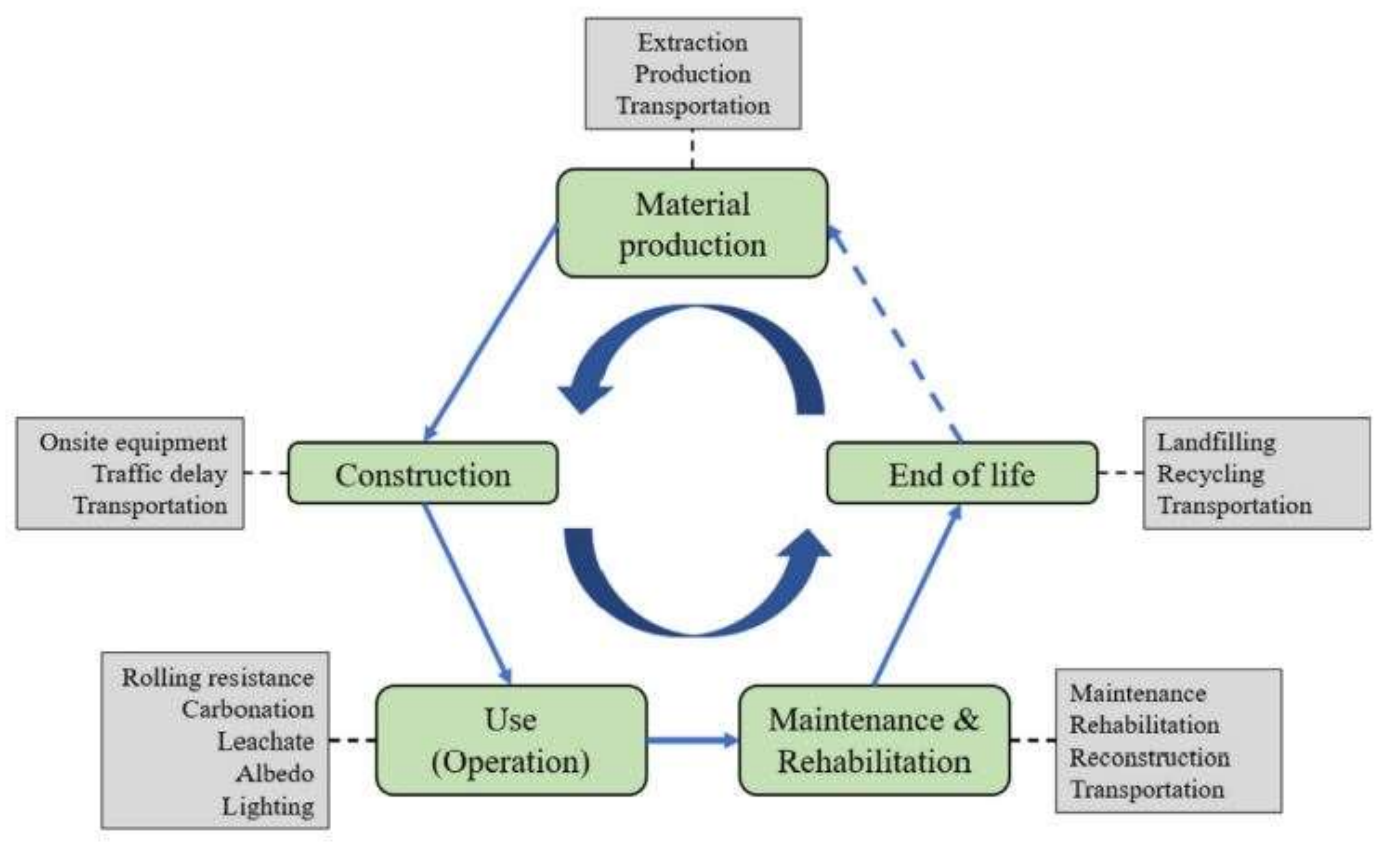

Figure 1 A generic pavement life cycle

\subsection{Pavement Types}

Generally, at this time there are two big households of pavement kinds. You'll find the adaptable and also the rigid pavements. Additionally there's a blend on the two types, the semi-rigid or semi-flexible pavements. The structure associated with an adaptable pavement consists of a number of bound as well as unbound layers which provides the pavement structural strength as well as as drainage as well as frost safeguards. With regard on the bound levels, it is made up basically of a mineral skeleton along with a bituminous binder, which might be supplemented with some ingredients. The scorching combination is spread to successive layers inside strips as well as mechanically compressed. The design associated with a good pavement demands the avoidance of permanent deformation (rutting) at reasonable to temperatures that are high, along with cracking during reduced temperatures

\subsection{Life Cycle Analysis (LCA)}

The idea of conducting a comprehensive evaluation on the life cycle of a procedure is a fairly recently available method of strategy that emerged in reaction to increased environmentally friendly understanding on the component of governments, the general public and industry. The precursors of life cycle evaluation as well as evaluation (LCA's) had been the global modelling studies as well as energy audits of late sixties in addition to first seventies. By doing this they desired to look at the resource cost as well as environmental implications of various patterns of man behaviour. LCAs have been an extension, as well as grew to be crucial that you help support the improvement of eco-labelling systems that are managing or even designed within a selection of nations round the world. For eco labels to become given, the awarding expert has to have the ability to assess the producing procedures required, the energy usage of use and manufacture, as well as the total as well as style of waste produced.

To effectively look at the burdens subjected to the environment by the creation of a task, the following of the use or a procedure of a particular course of action, two primary phases are engaged. The very first stage would be the group of data, and also the second will be the interpretation of that particular data. 


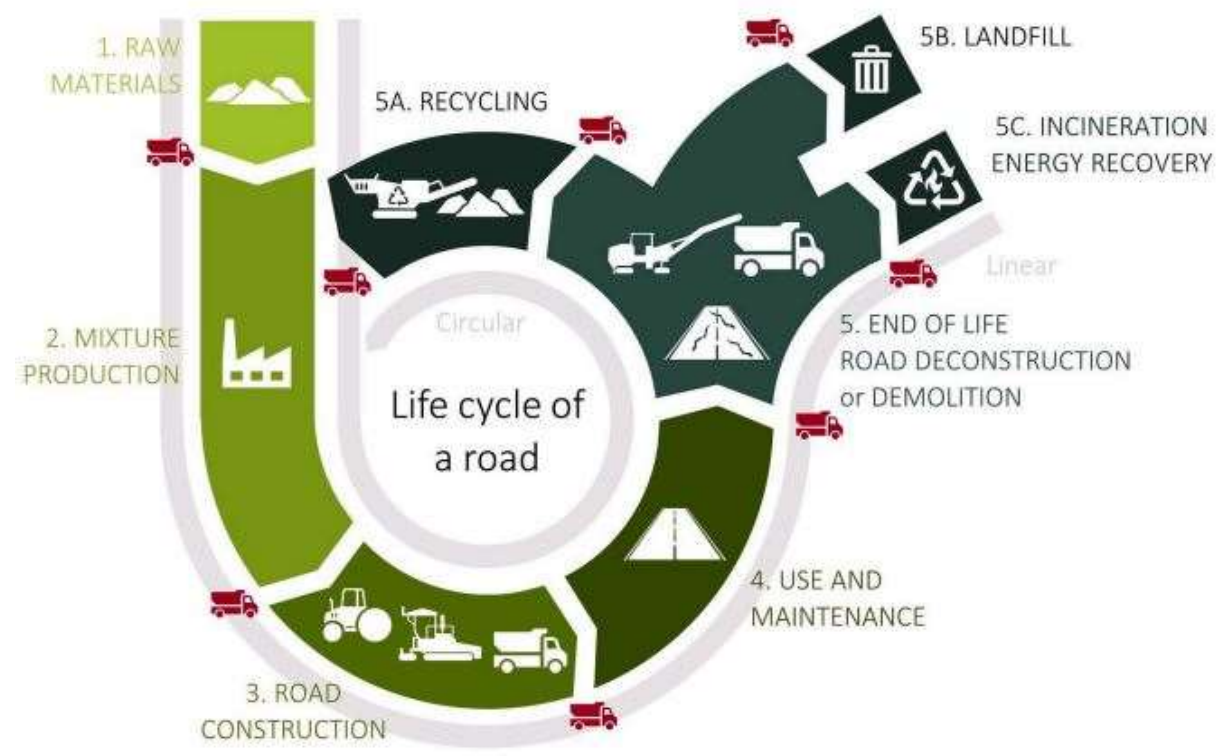

Figure 2 Life Cycle of a Road

\subsection{Problem Statement}

The primary issue arising with construction industry is of reducing the expected entire life cycle cost related to whole life of highways. Merely first cost is viewed while implementing costing of highways with very little or maybe absolutely nothing to consider of functioning, energy cost and maintenance cost.

\subsection{Scope of Project}

To get over this particular we've to compute LCC at base date looking at precious time importance of money as well as committing very inexpensive resolution on the road at first stage, using a thing to consider of some other pointed out expenses. This particular evaluation is going to help us to lessen LCC of framework as well as provides a bit better preserving via the lifetime of road.

\subsection{Objective}

1. The primary goal on this paper is calculating the entire price of concrete and bituminous pavements by making use of life cycle lost analysis (LCCA).

2. To Compare the general cost for 1 kilometre of each rigid and flexible pavements.

3. To recommend a much better option of the upkeep and also rehabilitation needed within bituminous pavements.

4. In order to study the life Cycle Cost Analysis.

\section{LITERATURE REVIEW}

Aditya Singh et.al (2020) (1) scientist discovers basically the most mainstream technique for investigating the asphalt usefulness of Indian thruways is unquestionably the static diversion strategy; this is typically cultivated by looking at the outcome on the asphalt on the applied burden. With this examination, the Falling Weight Deflect meter (Kgpback and fwd) had been utilized to evaluate the general exhibition of a road path of the National Highway inside the express of Haryana discovered India by looking at the diversion inside response on the heap put on during chose regions inside the turnpike. FWD was used to put an incredible burden on current asphalt and furthermore the reaction on the asphalt on the heap was evaluated. 
Moins et.al (2020) (2) Some specialists guarantee a hybridized eco-effectiveness assessment, which regularly melds life cycle assessment (LCA) to sort out the harmless to the ecosystem impact just as LCCA to discover the monetary impact, The goal on this paper is giving a best in class outline of prior techniques inside the more extensive space of LCCA for street projects. Hence, it can highlight genuine methods just as decide areas of interest to guarantee the heartiness of LCCA structures could be improved.

Priyesh Gour et.al (2020) (3) Author state a range of organizations make use of the LCCA method of calculate the financial feasibility of pavement layouts during a long haul. As a result, it is essential for recreation to reasonably assess pavement economics to provide ideal feedback on the LCCA. Over the final several years, a number of methods are created by institutions and agencies for pavement Life Cycle Cost Analysis (LCCA). While the commuter routes society has more and more been making use of LCCA as a crucial exercise, a number of businesses have actually created computer applications with regard to their LCCA techniques to help together with the evaluation. Present LCCA strategies are examined as well as LCCA software program is introduced to this specific document.

Kashmira Rasane et.al (2019) (4) researcher discovers the even with becoming an important section of national economies, contemporary roads system methods need a lot of national investments. So as to hold the caliber of the roadways at a suitable fitness level, a huge amount of investments for rehabilitation as well as upkeep tasks are essential along with investments in reconstructed and new highways. India has got the person of largest roads network throughout the globe, the range of life cycle being can vary therefore and considerably the outcomes are hypersensitive on the defined method boundaries. Road pc user prices in connection with road functions turns into a pertinent parameter of life cycle expense evaluation of pavements for selecting optimum option.

Jian-Shiuh Chen et.al (2019) (5) The assembling by items through the metallurgical business comprise of impact heater granulated slags, electric curve heater steel slags, alongside major genuinely necessary oxygen heater steel slags. Steel slag is typically viewed as an inexhaustible green substance of building programs, just as has for some time been put on to black-top asphalts as totals for surface region just as restricting project, The essential justification this specific paper is using life cycle cost assessment (LCCA) like a choice help instrument for three asphalt restoration techniques.

Jin Li et.al (2019) (6) The primary reason for this particular assessment ended up being to summary these current LCCA and LCA scientific studies related to the recycling where possible of reliable waste materials in deep freeway pavement as well as talk about the merits as well as demerits of existing is effective along with the upcoming exploration potentials, Firstly, based mostly around the pre-existing scientific studies, the use of virtually all reused solid waste material substances (e.g. recycled asphalt pavement, metal slag as well as coal fly ash) in deep highway pavement carried out satisfactorily as a result of the economic and environmental perspectives, concretely manifested within the decrease of energy use, greenhouse gas pollutants, other indicators and costs.

Hongmei Li et.al (2018) (7) with all the growth as well as development of highway system, an increasing number of highways satisfy different amounts of degeneration. Pavement upkeep, that typically aims to revive the comfortable and safe riding for road computer users, A situation when research over the highway network upkeep goal was conducted as an example the proposed process. A maximum of five pavement upkeep decision making associated variables have been viewed within the research, such as pavement efficiency, pavement system toughness, site traffic a lot, pavement grow old as well as highway grade. The weightings on the five variables have been quantified through AHP technique. 
Pokala Gopichand et.al (2018) (8) this process discovers essential program of management. variety and road style of authorities individual the LCCA method of assess the financial quality of road models during a lengthy yield. While the transportation society has steadily been making use of LCCA as a crucial stick to, a lot of organizations have actually created laptop applications for the LCCA approaches of theirs to be able to help together with the evaluation.

Sarfaraz Ahmed et.al (2017) (9) In order to prioritize pavement upkeep pursuits, a selection of choice generating approaches are already created as well as applied under Pavement Management System (PMS) study. These techniques differ against straightforward positioning to complicated optimization, Further, professionals foundation the decisions of theirs exclusively on the experience of theirs while concern isn't provided to the particular quantitative shape of all of the highways. In order to conquer the issues a goal dependent AHP technique is suggested with this research, in which pairwise comparability values are given based upon the gathered up area details through a street system of Mumbai community, comprising of 28 road areas.

Zhongyin Guo et.al (2016), (10) From the start of 2000, re-search as well as use of perpetual asphalt pavement (PP) engineering was deployed within China. The semi strict foundation for asphalt pavement continues to be typically deemed as common element of higher category freeways within the design based on the Chinese expertise after 1997.

\section{METHODOLOGY}

\subsection{Introduction}

This particular chapter details the technique within that the analysis would be to be completed. It identifies the way the info on the technique was gotten, choice on the sample sizing, information compilation as well as the way the information is now being handled. This particular chapter additionally enlightens the evaluation on the methodology as well as explanation of the test procedures as well as tactics. The statistical technique of the evaluation of the information is additionally discussed.

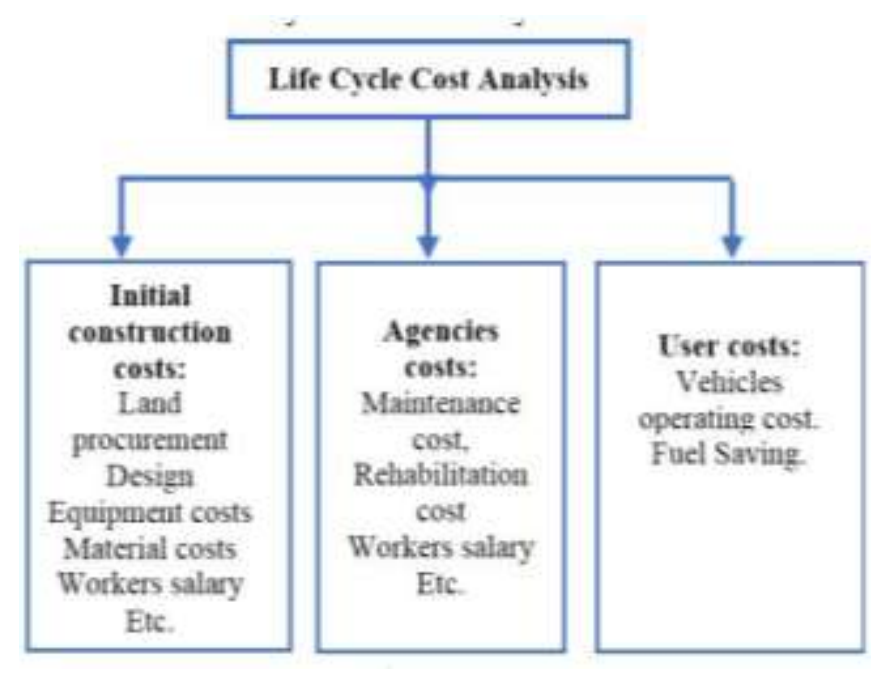

Figure 3 Row of Mthl Alignment at Sea-Link Site

\subsection{Research Design and Methodology}

Research design describes the overall plan for obtaining solutions to questions getting analyzed as well as for handling several of the issues encountered throughout the analysis; It's additionally defined within several point of view because the strategy or maybe intend to fix a 
research issue. Analysis layout requires within the excitement program via creating one thing significant therefore use the activity to get from' here' to' there' where' here' is identified when the original group of group of concerns to become clarified, and' there' is a bit of pair of realization with regards to the questions that entails a few of significant actions, therefore group of analysis and data of these pertinent data, Research methodology is determine being an organized search for relevant info and that leads to new understanding as well as compasses exploration into interactions along with various variables operating within a certain circumstance, It would be the study of problems with the usage of scientific principles and methods.

\subsection{Sources of Data}

The sources of information gathered for this particular study had been trusted equally secondary and primary information. Main data was comprised of the particular information or first-hand data from the site survey, questionnaires, interviews and observations. Secondary supply of information was obtained with the use of related books, magazines, journals and research papers. The kind of investigation strategy will be the triangulation, and that consists of the usage of equally qualitative and also the quantitative procedures.

\subsection{Selection of Data Collection Method}

You will find various way of group of data. It all depends on several elements and this incorporated area of review, option of info, period of study, attributes on the respondent, place of the research and many others. The objective of the study would be the most occasionally the paramount. Information collections are usually completed in a lot of ways as well as might be gotten by either a main source or maybe secondary source or perhaps both. The technique adopted for this specific study is primarily observations and questionnaire. Questionnaires as well as observations are efficient and effective method of gathering information but at times very hard if the distances are long apart. Questionnaires made up of a pair of concerns to that the respondents gave information and also might be a shut or even opened ended type. The kind of questionnaire used within this analysis was the shut finished type since time offered is short plus additionally, it entails some time to try and do the evaluation the information. To get quality information, the inquiries are straight, clear, and short on the stage. Having the problem of site survey visible assessment was carried out on the way the contractor stores the concrete components, the distance coming from the work spot, the kind of storage center they normally use as well as the way the site is now being shielded.

\subsection{Design And Development of Data}

In general, the look of the information was based upon group of info from building companies signed up together with the public university in Central and western Regions of Mumbai. This was about the basis of that which was to become achieved therefore the aims as well as goals. Pertinent literature likewise aided within the administering of the inquiries. All personnel along the construction site were probable respondents on the questionnaire The had been classified into categories:

- The first part included the general information from the construction firm, the background of the respondent and the role or position in the firm;

- The second portion asked questions on the material management practices, their storage facilities and the effect on the firm. 


\subsubsection{Distribution of Questionnaires}

Geographically, the analysis was completed solely found Mumbai and also the questionnaires had been created as well as personnel handed over to the representative or the contractor.

\subsection{Research Population and Sampling Techniques}

\subsubsection{Research Population}

Research population while the totality associated with a well-defined group of specific or maybe object which has a typical binding characteristics or even traits. It is able to additionally be described as a big group of individuals or maybe objects that will be the primary focus of a systematic query. The study addresses a public of twenty five (25) respondents comprised of building firms. This particular as a result of the point that they're the individuals that handle and also put construction materials in the site

- Target Population

It describes the whole team or maybe items to whose scientists are excited about generalizing the realization and possess different attributes. It's often referred to as theoretical public.

\section{- Accessible Population}

It refers towards the public within that the researcher is able to use the conclusions of theirs. It's a subset on the goal population and in addition often known as review population. It's from this particular the researcher attracts the sampling team.

\subsubsection{Sampling}

It's the procedure of selecting a percentage on the population to stand for the entire population. Sample group is surely a subset on the goal population. It's essential to decide on a sample group because is cheaper and also precious time conserving when compared with obtaining info coming from a bigger number of respondent. Each sample device needs to have exactly the same attributes to permit generalization of the end result to symbolize the target population. You will find two kinds of sampling strategies, specifically, likelihood as well as nonprobability sampling. The sort considered within the study is definitely the non-probability sampling.

\subsubsection{Non-Probability}

To sample the sampling method in which the samples are gathered to such a manner that it doesn't provide the person inside the public the same possibilities to be selected. A selection of sample group is remaining to the issue and the researcher of bias often arose. You will find various kinds of the method however the camera adopted will be the purposive sample as well as the snowball method. Purposive sampling method because will be the merely ways in which the target team may be gotten to very effortless and also the study can also be bounded by time; and also previously all of the sample isn't as large. Snowballing was utilized since several of the contractors aided within finding additional contractors belonging in one institution.

\subsection{Data Analysis}

The information gathered up as a result of the questionnaire was screened, edited to make sure readability and consistency. This was carried out by determining the typical response of every person from the various companies. The software for the evaluation was the Statistical Package for Social Science (SPSS) as well as Microsoft excel. Quantitative evaluation strategy was put to use within the information evaluation and also interpretation because the analysis is exploratory. It absolutely was ultimate summarized within the type of tables and charts and also had also been active in the categorization as well as ranking to achieve a variety of conclusions. 


\subsection{Location}

A metropolitan non-commercial part of seaside Mumbai is hard for review. The system is situated with Sewri region that is close to Greater Mumbai and also flood plains of river Kosi, Western portion of Mumbai as displayed within the fig 3.2. as well as fig 3.3. the spot is called as Sewri region. The dimensions of this place are 24 hectares. For producing the road for this spot, water is initially obtained within a subterranean tank (UGR) coming from water remedy plant that is around $7.0 \mathrm{kms}$ far from the non-commercial region. The UGR is attached to water treatment plant by a pipeline of $700 \mathrm{~mm}$ diameter. The topography of general area is flat with slope between $1 \%$ to $2 \%$. The spot Sewri is situated at longitude $77^{\circ} 12$ '22.9"E as well as latitude $28^{\circ} 46^{\prime} 08.4^{\prime \prime}$ N. Fig 3.1.3 shows satellite perspective of Mumbai.

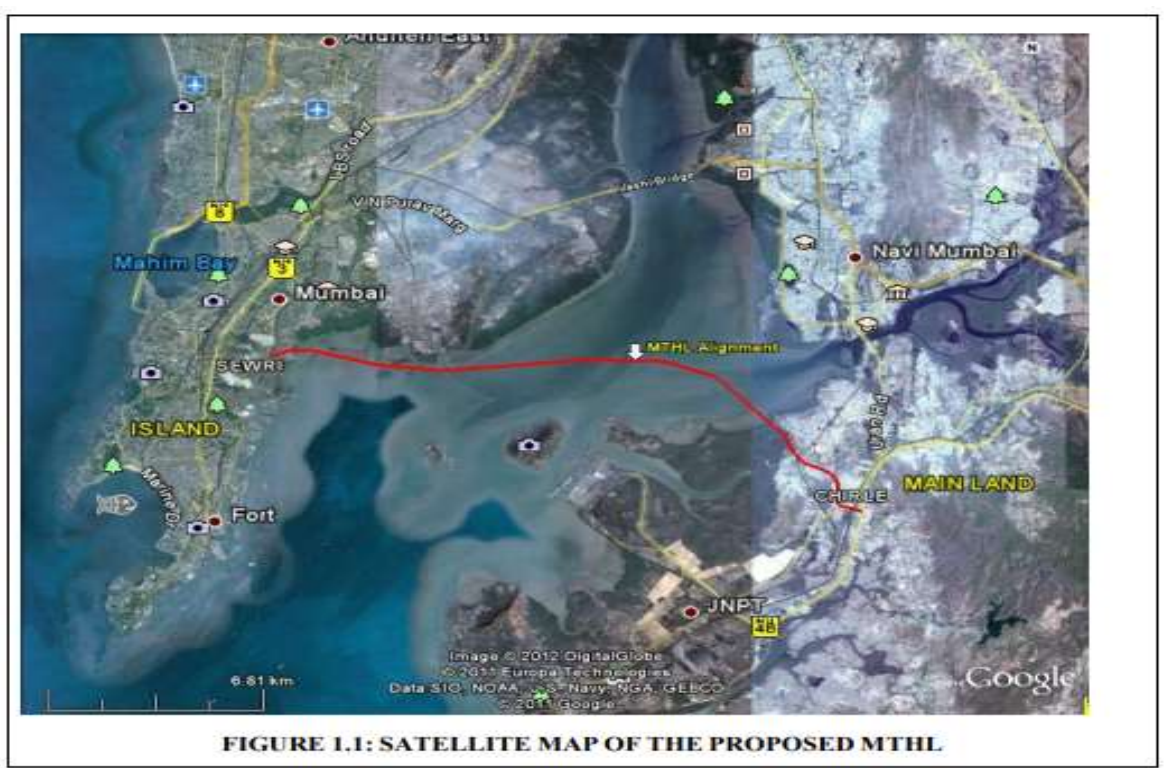

Figure 4 Location map of project area

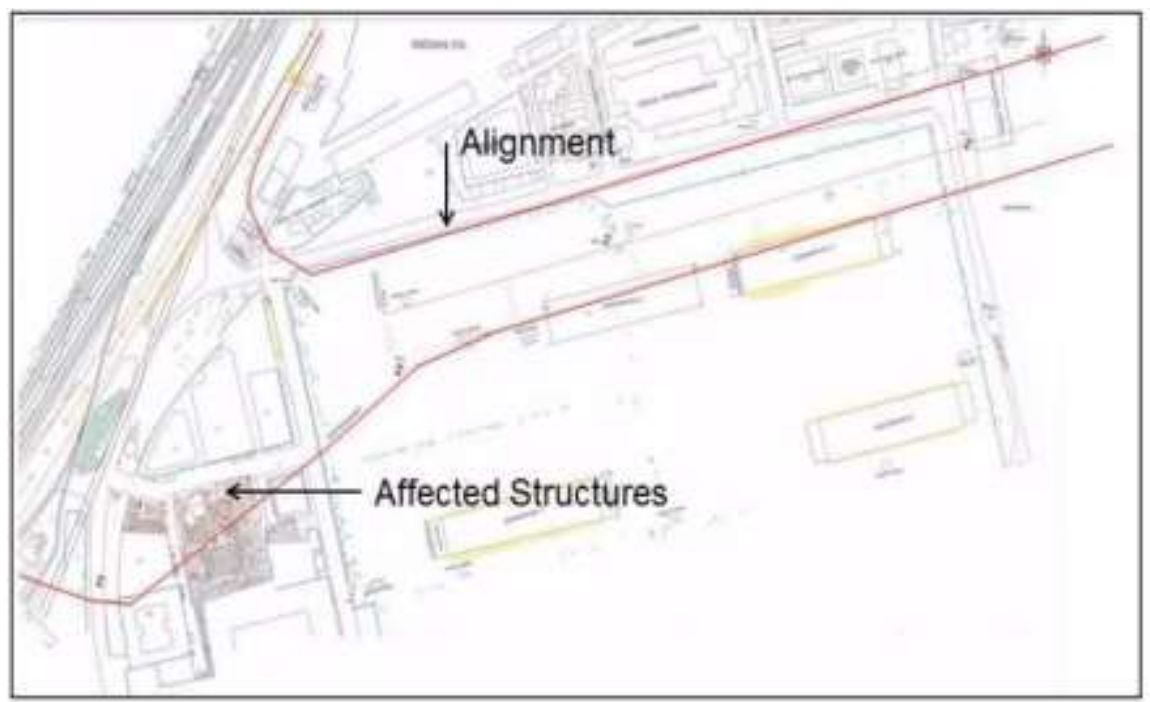

(Source-MMRDA)

Figure 5 Project Alignment and Affected Structures 


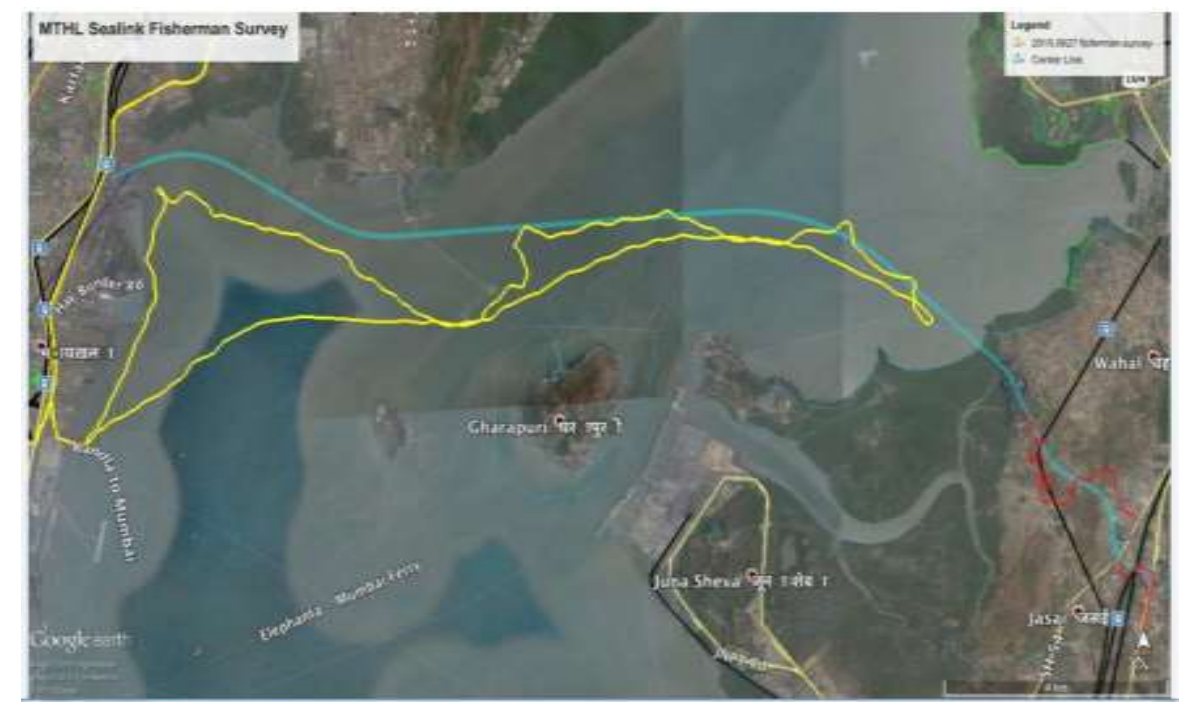

(Source-JICA study team)

Figure 6 GPS Track of the Site Visit as Per the Alignment of Mthl Sea-Link Section

The climate of the area is humid subtropical. The area experiences high humidity during the rainy season with heavy rainfall. There is high variation between summer and winter temperatures.

\section{RESULT AND DISCUSSION}

\subsection{Over View}

This section investigations the information gathered from the 25 respondents where the respondents were haphazardly browsed different development firms. This section manages the examinations and conversation of the capacity practices of built up substantial materials of contactors in the development firms in Mumbai.

\subsection{Demographic/Background Information}

This segment presents foundation data on different respondents. The foundation data remembered the respondent job for the development business, number of years practically speaking and the respondent's characterization of works

\subsubsection{Role in the Development Business}

The motivation behind this inquiry was to realize the respondent's position in the firm. They were to show whether they were building workers for hire, amount assessors, site administrator or undertaking director

Table 1 shows a synopsis of the jobs of respondents in the development business. The table obviously shows that $24 \%$ of our respondents were building project workers while $28 \%$ were amount assessors. A significant level of $40 \%$ were site bosses and the leftover task directors. This plainly legitimize the way that site administrators are not difficult to run over with while on location and are additionally able to answer the poll. 
Table 1 Role of respondents in the construction industry

\begin{tabular}{|c|c|c|c|}
\hline Role & Frequency & Percent (\%) & $\begin{array}{c}\text { Cumulative Frequency } \\
(\%)\end{array}$ \\
\hline Building Contractors & 6 & 24.00 & 24.00 \\
\hline Quantity surveyors & 7 & 28.00 & 52.00 \\
\hline Site supervisors & 10 & 40.00 & 92.00 \\
\hline Project managers & 2 & 8.00 & 100.00 \\
\hline Total & $\mathbf{2 5}$ & \multicolumn{2}{|c|}{$\mathbf{1 0 0 . 0 0}$} \\
\hline
\end{tabular}

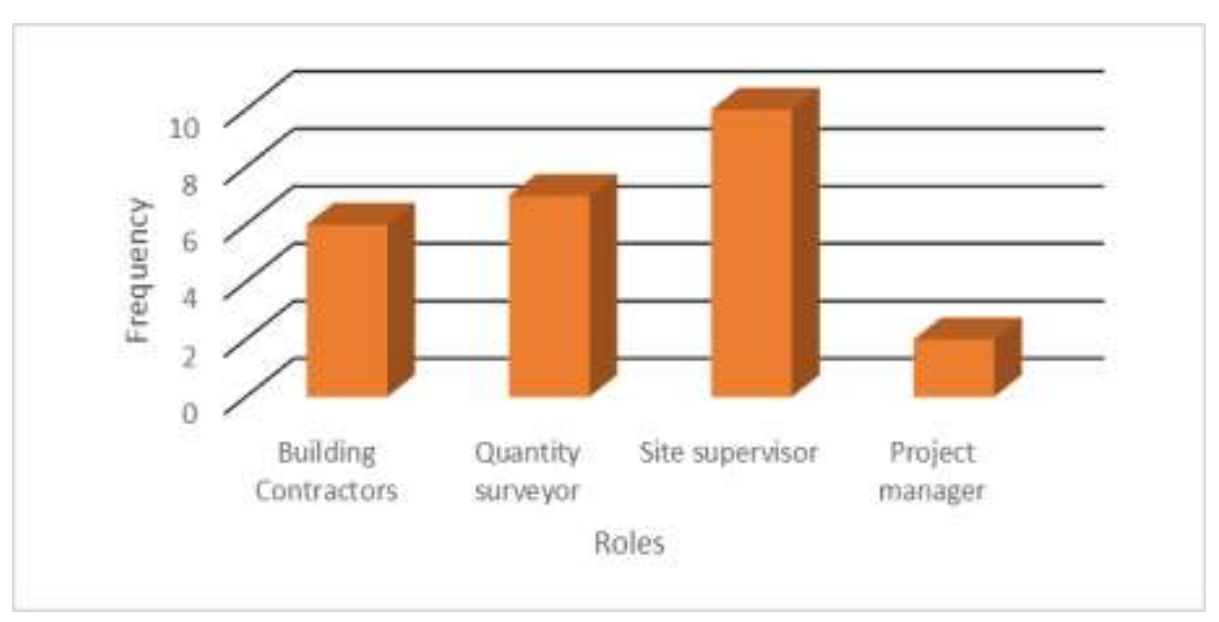

Figure 7 Role of respondents in the construction industry

\subsubsection{Number of Years of Practice of Respondents}

Table 2 underneath shows a rundown of respondent's years in help. The motivation behind this foundation data was to know the degree of involvement with their area. This data will offer importance to the nature of responses given out by the respondents. Additionally if respondents have acquired insight from working with their individual organizations, almost certainly, they are very much vexed away practices and cycles of built up concrete and this will approve their reaction that is required for this investigation. From the Table4.2, it is evident that a large portion of the respondents addressing 56\% have worked inside the scope of 5-10 years while a little level of four addressing only one respondent has worked for over 10 years .Only $8 \%$ of the respondents have worked for under 5 years while the leftover respondents $(32 \%)$ have worked between the long periods of 11-20. The various degrees of involvement acquired by the respondents will make the investigation truly plausible

Table 2 Respondents years of service

\begin{tabular}{|c|c|c|c|}
\hline Years of service & Frequency & Percent (\%) & Cumulative Frequency (\%) \\
\hline Less than 5 years & 2 & 8.00 & 8.00 \\
\hline $5-10$ years & 14 & 56.00 & 64.00 \\
\hline $11-15$ years & 4 & 16.00 & 80.00 \\
\hline $16-20$ years & 4 & 16.00 & 96.00 \\
\hline Greater than 20 & 1 & 4.00 & 100.00 \\
\hline Total & $\mathbf{2 5}$ & $\mathbf{1 0 0 . 0}$ & \\
\hline
\end{tabular}




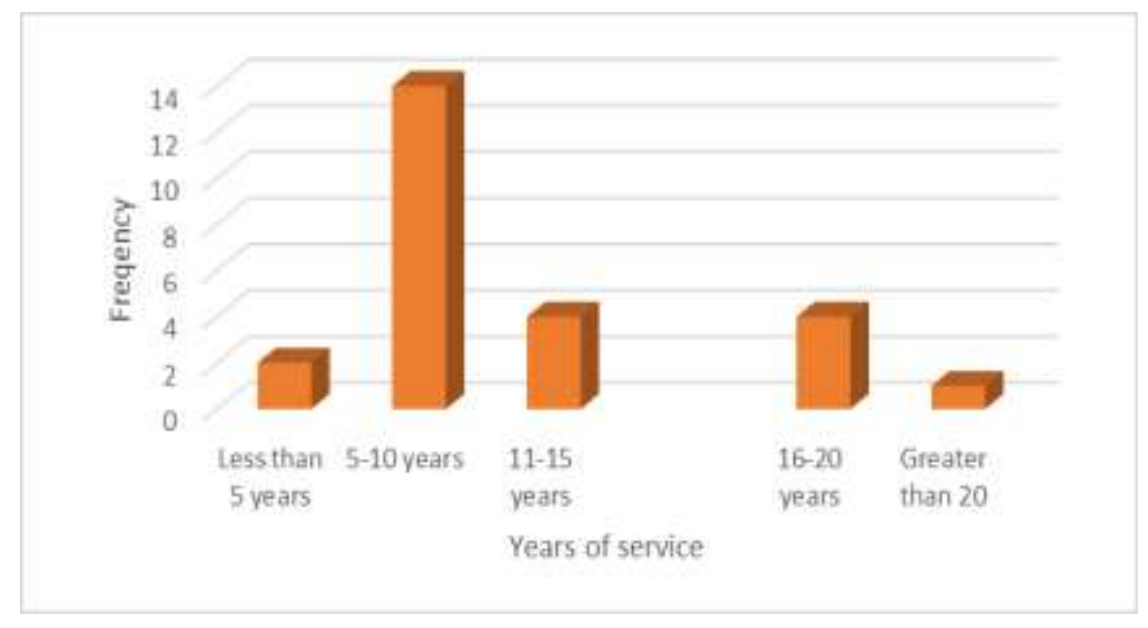

Figure 8 Respondents years of service

\subsubsection{Classification of Work}

Table 3 represents the summary of analyses of the classification of work of our respondents. This question shows the class of the respondent's company. Majority of our respondents (20) were under the D1K1 class which represents 80 percent. The remaining respondents (5) represent D2K2 contracting companies. This shows that our respondent's bases were mostly high profile construction companies.

Table 3 Classification of work

\begin{tabular}{|c|c|c|c|}
\hline Classification of work & Frequency & Percent (\%) & Cumulative Frequency (\%) \\
\hline D1K1 & 20 & 80.00 & 80.00 \\
\hline D2K2 & 5 & 20.00 & 100.00 \\
\hline D3K3 & 0 & 0.00 & 100.00 \\
\hline D4K4 & 0 & 0.00 & 100.00 \\
\hline Total & $\mathbf{2 5}$ & $\mathbf{1 0 0 . 0}$ & \\
\hline
\end{tabular}

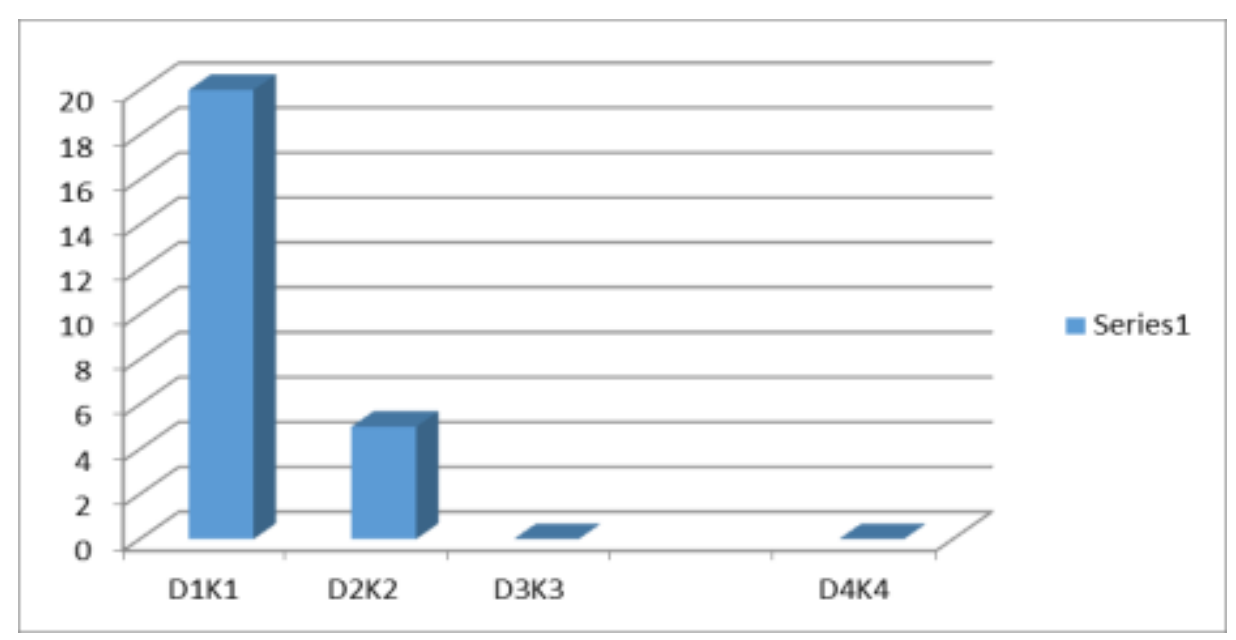

Figure 9 Classification of work

\subsection{Presentations and Descriptive Analysis of Data}

Capacity of supported substantial materials in the development business

The part of the poll offered respondents the chance to show by demonstrating on a five point Likert scale, the material administration rehearses, how explicit substantial materials are put away and the impact of helpless stockpiling of materials on the development business. 


\subsection{Life Cycle Cost Analysis}

Investigation period considered is 20 years beginning from 2016 . Rebate pace of $12 \%$ is considered according to government strategy and expansion pace of $5.5 \%$ has been considered at ascent of costs of material in future.

\subsubsection{Life Cycle Cost of Bituminous Pavements}

1) Construction cost of bituminous pavements.

Table 4 Construction Cost of Bituminous Pavements

\begin{tabular}{|c|c|c|c|c|c|}
\hline Pavement Crust & Cost $/ \mathrm{km}$ & Length (m) & $\begin{array}{l}\text { Thick ness } \\
\text { (mm) }\end{array}$ & $\begin{array}{l}\text { Wid th } \\
\text { (m) }\end{array}$ & Rate (Rs) \\
\hline $\begin{array}{l}\text { Bituminous } \\
\text { Concrete }\end{array}$ & $32,72,800$ & 1000 & 40 & 10 & $8182 /$ Cum \\
\hline Dense Bituminous & \multirow{2}{*}{$71,15,000$} & \multirow{2}{*}{1000} & \multirow{2}{*}{100} & \multirow{2}{*}{10} & \multirow{2}{*}{$7115 / \mathrm{Cum}$} \\
\hline Macadam & & & & & \\
\hline Wet Mix Macadam & $28,75,000$ & 1000 & 250 & 10 & $1150 /$ Cum \\
\hline Granular Sub-Base & $31,75,000$ & 1000 & 250 & 10 & $1270 / \mathrm{Cum}$ \\
\hline Prime Coat & $2,10,000$ & 1000 & 1 Coats & 10 & $21 / \mathrm{Sqm}$ \\
\hline Tack Coat & $3,50,000$ & 1000 & 2 Coats & 10 & $17.5 / \mathrm{Sq} \cdot \mathrm{m}$ \\
\hline Initial Cost & $1,69,97,800$ & & & & \\
\hline
\end{tabular}

\subsubsection{Support cost of bituminous asphalt}

Overlay will be given at each tenth year after development for fortifying of existing asphalt having a $75 \mathrm{~mm}$ DBM layer and $40 \mathrm{~mm}$ BC layer. Overlay cost is displayed in Table II.

As indicated by MoRTH rules a layer of $25 \mathrm{~mm}$ BC is to be given once in 5 years. Cost of overlays is displayed in Table III.

Table 5 Periodic Resurfacing in every Five Years (BC 25mm)

\begin{tabular}{|c|c|c|c|c|c|}
\hline $\begin{array}{c}\text { Pavement } \\
\text { Layer }\end{array}$ & $\begin{array}{c}\text { Cost/k } \\
\mathbf{m}\end{array}$ & $\begin{array}{c}\text { Length } \\
(\mathbf{m})\end{array}$ & $\begin{array}{c}\text { Thick(m } \\
\mathbf{m})\end{array}$ & $\begin{array}{c}\text { Width } \\
(\mathbf{m})\end{array}$ & $\begin{array}{c}\text { Rate } \\
(\mathbf{R s})\end{array}$ \\
\hline $\begin{array}{c}\text { Bituminous } \\
\text { Concrete }\end{array}$ & $2,045,50$ & 1000 & 25 & 10 & $8182.0 / \mathrm{Cum}$ \\
\hline
\end{tabular}

\begin{tabular}{|c|c|c|}
\hline Year & $\begin{array}{c}\text { Cost per } \\
\text { Km. }\end{array}$ & Inflated Cost $\mathbf{a} \mathbf{5 . 5 0} \%$ p.a. \\
\hline $5^{\text {th }}$ Year & $2,045,500$ & $2,820,422.96$ \\
\hline $14^{\text {th }}$ Year & $2,045,500$ & $4,566,530.66$ \\
\hline $18^{\text {th }}$ Year & $2,045,500$ & $5,657,130.76$ \\
\hline Total & $6,136,500$ & $13,044,084$ \\
\hline
\end{tabular}


Cost Comparative Analysis of RCC Mode of Pavement Construction for Mumbai Coastal Road Project

Table 6 Cost of Overlay to be provided at every 10th year

\begin{tabular}{|c|c|c|c|c|c|}
\hline $\begin{array}{c}\text { Overlay } \\
\text { Layer }\end{array}$ & $\operatorname{Cost} / \mathbf{k m}$ & Length(m) & Thick(mm) & Width(m) & Rate(Rs) \\
\hline $\begin{array}{c}\text { Bituminous } \\
\text { Concrete }\end{array}$ & $32,72,800$ & 1000 & 40 & 10 & $\begin{array}{l}8182 \\
\text { Cum }\end{array}$ \\
\hline $\begin{array}{c}\text { Dense } \\
\text { Bituminous } \\
\text { Macadam }\end{array}$ & $53,36,250$ & 1000 & 75 & 10 & $7115 / \mathrm{Cum}$ \\
\hline \multirow[t]{2}{*}{ Tack Coat } & \multirow{2}{*}{$3,50,000$} & 1000 & 2 & 10 & \multirow{2}{*}{$\begin{array}{l}17.5 \\
\text { Sqm. }\end{array}$} \\
\hline & & & Coats & & \\
\hline Initial Cost & $89,59,050$ & & & & \\
\hline
\end{tabular}

\begin{tabular}{|c|c|c|}
\hline Overlay Year & Initial Cost (Rs) & Inflated Cost @ $5.50 \%$ p.a. \\
\hline 10 th Year & $8,959,050$ & $16,145,035,95$ \\
\hline Total & $8,959,050$ & $16,145,036$ \\
\hline
\end{tabular}

\section{2) Life Cycle Cost of Concrete Pavement}

Construction Cost of Concrete Pavements

Table 7 Construction Cost of Concrete Pavements

\begin{tabular}{|c|c|c|c|c|c|}
\hline Pavement Layer & Cost $\mathrm{km}$ & $\begin{array}{c}\text { Length } \\
(\mathrm{m})\end{array}$ & Thick(mm) & Width(m) & Rate(Rs) \\
\hline PQC & $1,72,23,000$ & 1000 & 300 & 10 & $5741.0 / \mathrm{cum}$ \\
\hline DLC layer & $25,96,000$ & 1000 & 100 & 10 & $2596.0 /$ Cum \\
\hline GSB Layer & $31,75,000$ & 1000 & 250 & 10 & 1270.0 Sqm \\
\hline Initial Cost & $2,29,94,000$ & & & & \\
\hline
\end{tabular}

Support cost of Concrete Pavements

Joint Sealing: $50 \%$ of the joint sealants are to be supplanted in like clockwork:

Joint Length: Contraction Joint length per km. for 10m wide carriageway 10000m

Longitudinal Joint length for $1 \mathrm{~km}$ and two joints in $10 \mathrm{~m}$ width $10000 \mathrm{~m}$

Length to be supplanted like clockwork is $30 \%$ of all out length

Contraction joint $=3333.333 \mathrm{~m}$

Longitudinal joint $=3333.333 \mathrm{~m}$

Cost of joint seals in shown in Table $V$ 
Anamika Dilip Jaiswal and Raju Narwade

Table 8 Cost of Joint Seals (Preformed Seals) per Km

\begin{tabular}{|c|c|c|}
\hline \multicolumn{2}{|c|}{ Maintenance Cost of Joints Sealing } \\
\hline Maintenance Year & Maintenance Cost (Rs.) & $\begin{array}{c}\text { Inflated Cost } \mathbf{a} \mathbf{5 . 5 0} \% \\
\text { p.a. }\end{array}$ \\
\hline 5 th Year & $8,33,333$ & $11,49,035.67$ \\
\hline 10 th Year & $8,33,333$ & $15,01,743.67$ \\
\hline 15 th Year & $8,33,333$ & $19,62,718.92$ \\
\hline 20 th Year & $8,33,333$ & $25,65,195.13$ \\
\hline Total & $33,33,333$ & $71,78,693$ \\
\hline
\end{tabular}

\section{Concrete Spalling}

$0.5 \%$ of Joint length for a width of $500 \mathrm{~mm}$ in every 10 years 10 th year spalling concrete $=50$ Sqm, Repairs of concrete spalling $=50 * 6889.2=$ Rs 344460

Table 9 Total Cost and Inflated Cost of Concrete Spalling

\begin{tabular}{|l|c|c|}
\hline \multicolumn{3}{|c|}{ CONCRETE SPALLING } \\
\hline $\begin{array}{l}\text { Maintained } \\
\text { Year }\end{array}$ & Maintenance Cost (Rs.) & Inflated Cost $\mathbf{a 5 . 5 0 \%}$ P.a. \\
\hline 10th Year & $3,44,460$ & $6,20,748,75$ \\
\hline Total & $3,44,460$ & $6,20,749$ \\
\hline
\end{tabular}

\subsection{Life Cycle Cost of Overlays}

\subsubsection{Life Cycle Cost of Bituminous Overlays}

Bituminous Overlays

Table 10 LCC of Bituminous Overlays

\begin{tabular}{|l|r|r|}
\hline \multicolumn{3}{|c|}{ Bituminous Overlays } \\
\hline Overlay & \multicolumn{1}{|c|}{ Initial Cost } & \multicolumn{1}{|c|}{ Inflated cost } \\
\hline Strengthening overlay & $89,59,050$ & $1,61,45,036$ \\
\hline Periodic overlays & $61,36,500$ & $1,30,44,084$ \\
\hline Total & $1,50,95,550$ & $2,91,89,120$ \\
\hline
\end{tabular}

\subsubsection{Construction cost of Thin White topping overlay}

Table 11 Thin White topping overlay

\begin{tabular}{|l|c|c|c|c|c|}
\hline $\begin{array}{c}\text { Pavement } \\
\text { Layer }\end{array}$ & Cost/km & $\begin{array}{c}\text { Length } \\
(\mathbf{m})\end{array}$ & $\begin{array}{c}\text { Thick } \\
(\mathbf{m m})\end{array}$ & $\begin{array}{c}\text { Width } \\
(\mathbf{m})\end{array}$ & $\begin{array}{c}\text { Rate } \\
(\text { Rs })\end{array}$ \\
\hline $\begin{array}{l}\text { Thin White } \\
\text { topping } \\
\text { (TWT) }\end{array}$ & $86,11,500$ & 1000 & 150 & 10 & $\begin{array}{c}5741 \\
/ \mathrm{Cum}\end{array}$ \\
\hline Milling & 26,775 & 1000 & 50 & 10 & $53.6 / \mathrm{Cum}$ \\
\hline Initial Cost & $86,38,300$ & & & & \\
\hline
\end{tabular}




\begin{tabular}{|l|c|c|c|c|}
\hline \multicolumn{1}{|c|}{ Item } & Unit & Quantity & $\begin{array}{c}\text { Rates } \\
\text { (Rs.) }\end{array}$ & Cost/Km. \\
\hline Contraction joint & $\mathrm{m}$ & $3333.333 \mathrm{~m}$ & 150 & 500000 \\
\hline Longitudinal Joint & $\mathrm{m}$ & $3333.333 \mathrm{~m}$ & 100 & 333333.33 \\
\hline & & & Total & 833333.33 \\
\hline
\end{tabular}

\subsubsection{Construction cost of Ultra-Thin White topping overlay}

Table 12 Ultra-Thin White topping Overlay

\begin{tabular}{|c|c|c|c|c|c|}
\hline $\begin{array}{c}\text { Pavement } \\
\text { Layer }\end{array}$ & Cost/km & $\begin{array}{c}\text { Length } \\
(\mathbf{m})\end{array}$ & $\begin{array}{c}\text { Thick } \\
(\mathbf{m m})\end{array}$ & $\begin{array}{c}\text { Width } \\
(\mathbf{m})\end{array}$ & $\begin{array}{c}\text { Rate } \\
(\mathbf{R s})\end{array}$ \\
\hline $\begin{array}{c}\text { Thin White } \\
\text { topping } \\
\text { (UTWT) }\end{array}$ & $57,41,000$ & 1000 & 150 & 10 & $\begin{array}{c}5741 \\
\text { Cum }\end{array}$ \\
\hline Milling & 26,775 & 1000 & 50 & 10 & $53.6 / \mathrm{Cum}$ \\
\hline Initial Cost & $57,67,800$ & & & & \\
\hline
\end{tabular}

4.5.4. Maintenance cost for concrete overlays will be same as that of new concrete roads.

Table 13 Maintenance cost of Concrete Pavements

\begin{tabular}{|c|c|c|}
\hline Stages & Initial cost & Inflated cost \\
\hline Joint sealing & $3,333,333$ & $7,178,693$ \\
\hline Concrete spalling & 344,460 & 620,749 \\
\hline Total & $3,677,793$ & $7,799,442$ \\
\hline
\end{tabular}

\section{Road User Cost}

\section{Vehicle Operating Cost (VOC)}

Client cost are those that borne by the vehicles that movement out and about. These expense involve Vehicle Operating Cost (VOC), time expenses of traveller and items on the way and mishap cost. In the Present examination, just VOC is thought of, expecting the other two expenses are equivalent in the two kinds of asphalts. VOC comprises of mileage of vehicle, fuel, ointments, deterioration and fixed expense. It has been seen that a very much developed bituminous substantial surface has a smooth riding quality with an unpleasantness file around $2000 \mathrm{~mm} / \mathrm{km}$ however the riding quality crumble with traffic and may arrive at worth of harshness of $4000 \mathrm{~mm} / \mathrm{km}$ in a couple of years and reestablishment wearing course is given at the stage to further develop the riding quality. Then again, starting unpleasantness of concrete substantial surface is kept up with nearly for the duration of its existence with very little disintegration, for correlation of life cycle cost, harshness of bituminous surface is taken as $3000 \mathrm{~mm} / \mathrm{km}$ and for substantial surface $2000 \mathrm{~mm} / \mathrm{km}$.

It is found from IRC SP: 30 Manual of monetary assessment for transportation projects. Yearly development in rush hour gridlock $7.5 \%$ and expansion pace of $7.5 \%$ is thought of.

VOC is determined as VOC each year $=($ No. of vehicle each day $) *(365) *($ VOC Rs $/ \mathrm{km})$

Computation of VOC is displayed in Table XI 
Traffic volume overview was directed physically for three days, twelve hours day by day and number of business vehicles each day were thought of.

Table 14 Traffic Volume Count

\begin{tabular}{|c|c|c|c|c|c|c|}
\hline Site Name & \multicolumn{3}{|c|}{ Sewree Chowk } & \multicolumn{3}{c|}{$\begin{array}{c}\text { Mumbai sewri, } \\
\text { Charholi }\end{array}$} \\
\hline & \multicolumn{3}{|c|}{ CVPD } & \multicolumn{3}{c|}{ CVPD } \\
\hline Day & D1 & D2 & D3 & D1 & D2 & D3 \\
\hline Time(9am to 9pm) & & & & & & \\
\hline $9.00-10.00$ & 58 & 61 & 58 & 58 & 59 & 63 \\
\hline $10.00-11.00$ & 61 & 58 & 58 & 59 & 64 & 61 \\
\hline $11.00-12.00$ & 48 & 51 & 55 & 69 & 67 & 64 \\
\hline $12.00-01.00$ & 53 & 55 & 52 & 57 & 61 & 59 \\
\hline $01.00-02.00$ & 49 & 47 & 52 & 52 & 48 & 47 \\
\hline $02.00-03.00$ & 55 & 51 & 47 & 45 & 53 & 43 \\
\hline $03.00-04.00$ & 48 & 50 & 49 & 58 & 56 & 55 \\
\hline $04.00-05.00$ & 50 & 48 & 53 & 54 & 51 & 59 \\
\hline $05.00-06.00$ & 55 & 53 & 55 & 61 & 59 & 66 \\
\hline $06.00-07.00$ & 57 & 61 & 60 & 53 & 66 & 61 \\
\hline $07.00-08.00$ & 62 & 58 & 56 & 58 & 61 & 60 \\
\hline $08.00-09.00$ & 63 & 60 & 65 & 68 & 67 & 66 \\
\hline Total & 659 & 653 & 660 & 692 & 712 & 704 \\
\hline Average & & 657.33 & & & 702.67 & \\
\hline & & 657 & & & 703 & \\
\hline & & & & & & \\
\hline
\end{tabular}

\section{Fuel Saving}

In USA, a study was made and it was observed that there is fuel saving of $20 \%$ on concrete road as compared to bituminous roads having same roughness index.

In India, central road research institute (CRRI), New Delhi also made similar study on Delhi-Agra (NH-2) and found that there is a fuel saving of $14 \%$ on concrete roads as compared to bituminous roads for commercial vehicles. Due to increase in traffic on roads and rising in the fuel prices in the international market, the impact of fuel saving has been found quite important as compared to extra initial cost of concrete road over bituminous road.

A case study on Durable and cost effective concrete overlay on city bituminous roads: White topping by Binod Kumar, Scientist, CRRI also states that there is $10 \%-15 \%$ fuel saving for heavy vehicles on concrete roads.

Annual fuel saving $(\mathrm{Rs})=$ No. of CVPD $* 365 * 14 / 100 * 1 / 4 * 5814 / 100=14 \%$ fuel saving, $1 / 4=(4 \mathrm{~km}$ per litre $)$, Inflation rate $-5 \%$ in diesel cost

Calculation of Fuel saving is shown in table 4.15

Life cycle cost comparison of new bituminous and concrete pavements is shown in Table 4.15

Life Cycle Cost Comparison of New Bituminous Pavements 4.16

\subsection{Optimality in Road Fund Allocation}

1. Satisfactory financing is fundamental for feasible street support systems since street decay is a nonstop interaction after an underlying venture. Anyway street support is portrayed with subsidizing shortages. Because of the issue of restricted financing ideal use of restricted assets is fundamental. The hypothetical points of view of street speculation investigation are either founded on guaranteeing financial proficiency or value. As of now the key test is the manner by which to viably accomplish the two destinations for street store assignment. 
2. The mission for ideal street reserve portion is characterized as far as guaranteeing monetary proficiency for most extreme returns and responsibility to the patrons of the asset. Along these lines Multi rules investigation (MCA), are seen as the choice worldview for resolving this issue.

3. MCA application in transportation is restricted and there are no standards. There is likewise a viewpoint in street venture investigation that street support doesn't create more extensive social effects however the issue isn't checked in Literature. The correlation of a deterministic way to deal with street reserve allotment with no thought for more extensive social points of view and an expressed inclination based method with the consideration of more extensive social has managed the cost of this investigation to mention the accompanying objective facts.

\subsection{Outcome of this Project with Deterministic Approach}

The model with a deterministic way to deal with street reserve distribution was applied with the street as a result of its status. It depended on not really settled from the actual properties of a street and the limit of mindful offices to accomplish set targets. It likewise remembered contemplations for market instruments and balance for the premise of transport moderateness. The aftereffect of the examination showed that the deterministic way to deal with street reserve assignment brought about the portion of higher extents of the street store on value reason for all street types. It is hence inferred that it is feasible to designate higher extents of the street store based on value than proficiency contemplations with a street reserve allotment strategy dependent on quantitative examination.

\section{CONCLUSION}

This exposition, which basically dives into cost near examination of supported substantial asphalt in the development business is partitioned into five (5) free however interrelated sections. The primary prologue to the exploration canvassed in Chapter One. . In Chapter3, the system embraced for the investigation including the philosophical positions, research plan, and exploration procedure was examined. The examination interaction was in a single fundamental stage; review surveys. Section 4 introduced the exact examination and gave nitty gritty conversations on the review results. This section (Chapter 5) sums up the issues tended to all through the investigation. It starts with an outline of how the exploration goals were accomplished, trailed by commitments of this examination to information. The part closes with suggestions for additional exploration that can be directed dependent on the ends and restrictions of the examination.

1) Life cycle cost investigation shows that regardless of whether the underlying expense of substantial asphalts is high the net present worth of substantial asphalts is Rs 193 lakhs $/ \mathrm{km}(5 \%)$ not exactly bituminous asphalts.

2) Life cycle cost investigation of overlays shows that the net present worth of super slim white garnish is Rs 283 lakhs $/ \mathrm{km}$ (7\%) less and of slender white fixing is Rs 254 lakhs $/ \mathrm{km}(6 \%)$ not exactly the expense of bituminous overlays

3) When the net present worth of bituminous overlays and substantial white garnishes disregarding vehicle working expense and fuel saving the complete expense of bituminous overlays is Rs 172 lakhs and that of substantial white fixings is Rs 107 lakhs for flimsy white fixing and Rs 78 lakhs for super dainty white fixing, which is $38 \%$ and $55 \%$ lesser than bituminous overlays.

4) LCCA reasons that substantial asphalts are more valuable than bituminous asphalts and cement overlays can be considered as useful choice for recovery of existing bituminous asphalts. 
5) The result of the effect of the way to deal with street store assignment with the current strategy gave a lower return as far as the effect on asphalt unpleasantness execution. This is on the grounds that a higher extent is given to metropolitan streets. Metropolitan street present the greatest expense segments because of better expectations however has a more limited street length. Hence a higher extent of assets to metropolitan streets don't goodly affect the whole street network as far as asphalt harshness execution.

\section{REFERENCES}

[1] Aditya Singha, Akash Sharmab, Tanuj Chopra Analysis of The Flexible Pavement Using Falling Weight Deflectometer for Indian National Highway Road Network, World Conference on Transport Research - WCTR 2019 Mumbai 26-31 May 2019, Transportation Research Procedia 48 (2020) 3969-3979

[2] B. Moins, C. France, W. Van den bergh, A. Audenaert, Implementing living cycle expense evaluation contained highway engineering: A crucial comment on methodological framework choices, Renewable and also Sustainable Energy Reviews, Renewable as well as Sustainable Energy Reviews 133 (2020) 110284

[3] Priyesh Gour, Dr. Shalini Yadav, Evaluation of pavement living cycle expense evaluation: Analysis and Review by programs, International Journal and computer tools of Engineering Development as well as Research, ISSN: 23219939 | OIJEDR 2020 Year 2020, Volume eight, Issue three

[4] Kashmira Rasane, Harshita Ambre, A Study on life cycle Cost Analysis for Roads, International Research Journal of Technology and Engineering (IRJET) e ISSN: 2395-0056Volume: six Issue: five | May 2019

[5] Jian-Shiuh Chen, Chin Hung Yang, Cheng Te Lee, Field analysis of porous asphalt training course for life cycle price analysis, Construction as well as Building Materials,221 (2019) 2026

[6] Jin Li, Feipeng Xiao, Lanfang Zhang, Serji N. Amirkhanian, Life cycle evaluation as well as living cycle expense evaluation of reused sound trash resources in deep freeway pavement: $A$ review,/ Journal of Cleaner Production 233 (2019) 1182e1206

[7] Seven Hongmei Li a, Fujian Ni b, Qiao Dong c, Yuqin Zhu. Application of analytic hierarchy procedure contained community amount pavement upkeep decision making, International Journal of Pavement Research as well as Technology eleven (2018) 345-354

[8] Pokala Gopichand, A Conditional Study on Life Cycle Cost Analysis for Roads, International Journal of Innovative Research in Technology, IJIRT | Volume five Issue six | ISSN: 2349-6002

[9] Sarfaraz Ahmed P. Vedagiri one, K.V. Krishna Rao Prioritization of pavement upkeep areas making use of unbiased based Analytic Hierarchy Process, / International Journal of Pavement Research as well as Technology ten (2017) 158-170

[10] Zhongyin Guo a, Saud A. Sultan, Feasibility of perpetual pavement phase building in deep China: A lifetime cycle expense evaluation, International Journal of Transportation Science as well as Technology five (2016) 239-247

[11] Peyman Babashamsi, Nur Izzi Md Yusoff a, Halil Ceylan b, Nor Ghana Md Nor c, Hashem Salarzadeh Jenatabadi Evaluation of pavement living cycle expense evaluation: Analysis and 
Review, International Journal of Pavement Research as well as Technology nine (2016) 241254

[12] Yara Hamdar, Ghassan R. Chehab as well as Issam Srour, Life Cycle Evaluation of Pavements: A crucial Review, Journal of Engineering Science as well as Technology Review nine (six) (2016) 12 twenty six

[13] Yonas Ketema, Prof. Emer T. Quezon, Getachew Kebede, Cost and also Benefit Analysis of Flexible and rigid Pavement: A Case Study at Chancho-Derba-Becho Road Project, International Journal of Scientific \& Engineering Research, Issue 10, Volume 7, October 2016 181 ISSN 2229-5518

[14] Sonia Rahman, BSc, Andrew B. Northmore, PhD, Vimy Henderson, EIT, MASc, PEng and also Susan L. Tighe, PhD, PEng, Developing A Framework for Low Volume Road Implementation of Pervious Concrete Pavements, International Journal of Transportation Science as well as Technology vol. four no. one 2015 - web pages seventy seven - ninety two seventy seven

[15] Michael A-A. Okae Adow, Boris K and Seth Emmanuel Allotey. Sasraku-Neequaye. Comparative Cost Analysis in between Concrete Pavement and asphalt Pavement in Road Construction: A Case analysis utilizing Concrete quality 35, Civil as well as Environmental Research www.iiste.org ISSN 22245790 (Paper) Vol.7, No.10, 2015

[16] Changmo Kim, John T, Eul-Bum Lee. Harvey, Amy Fong as well as Ray Lott, Automated Sequence Selection and also Cost Calculation for Rehabilitation and Maintenance in Highway Life Cycle Cost Analysis (LCCA), International Journal of Transportation Science as well as Technology vol. four no. one 2015 - web pages sixty one - seventy six

[17] Geethu Saji, Sreelatha. T, B.G Sreedevi, A Case Study on Overlay Design Using HDM 4, International Journal of Innovative Research in Science, Technology and Engineering An ISO 3297: 2007 Certified Organization, Volume two, Special Issue one, December 2013 Proceedings of International Conference on Environment-2013 and Energy (ICEE 2013) 